\title{
Stability Analysis of Mathematical Modeling of Interaction between Target Cells and COVID-19 Infected Cells
}

\author{
Sugiyanto $^{1 *}$, Mansoor Abdul Hamid ${ }^{2}$, Alya Adianta ${ }^{1}$, Hanny Puspha Jayanti ${ }^{1}$, Muhammad Ja'far Luthfi ${ }^{3}$ \\ ${ }^{1}$ Mathematics Department, Faculty of Science and Technology, Universitas Islam Negeri Sunan Kalijaga, Indonesia. \\ ${ }^{2}$ School of Food Science \& Nutrition, Universiti Malaysia Sabah, Malaysia. \\ ${ }^{3}$ Department of Biological Education, Faculty of Tarbiyah and Education, Universitas Islam Negeri Sunan Kalijaga, Indonesia.
}

\author{
Corresponding author* \\ sugiyanto@uin-suka.ac.id
}

Manuscript received: 19 October 2021. Revision accepted: 30 October, 2021. Published: 02 November, 2021.

\begin{abstract}
The stability analysis in this mathematical model was related to the infection of the Coronavirus Disease 2019 (Covid-19). In this mathematical model there were two balance points, namely the point of balance free from Covid-19 and the one infected with Covid-19. The stability of the equilibrium point was influenced by all parameters, i.e. target cells die during each cycle, number of target cells at $t^{\prime}=$ 0 , target cells infected during each cycle based on virion unit density, effective surface area of the network, the ratio of the number of virus particles to the number of virions, infected cells die during each cycle, the number of virus particles produced by each infected cell during each cycle, and virus particles die during each cycle. In the simulation model, immunity is divided into high, medium and low immunity. For high, moderate and low immunity, respectively, the highest number of target cells is in high, medium and low immunity, whereas for the number of infected cells and the number of Covid-19, it is in the opposite sequence of the number of target cells.
\end{abstract}

Keywords: Coronavirus Disease 2019; Equilibrium point stability; target cells and infected cells.

\section{INTRODUCTION}

Coronavirus Disease 2019 (Covid-19) was first known to infect residents in Wuhan City, China, and was notified by the Chinese Government to WHO in December 2019 (Sugiyanto \& Abrori, 2020). Covid-19 belongs to subfamily Orthocoronavirinae, family Coronaviridae, and order Nidovirales (Tan et. al., 2020). About $80 \%$ of Covid-19 illness show mild symptoms and $20 \%$ have severe symptoms. Some of the $20 \%$ patients who contract Covid-19 develop severe pneumonia, sometimes with acute respiratory distress, which can lead to organ failure and death.

The stability analysis of mathematical modeling is used to determine the recovery period of Covid-19 patients. There are many factors that determine a person would get into mild, severe or severe symptoms. We can classify these symptoms into three things depend on the immunity of the Covid-19 patient. In this modeling, categorization were done using the $\mathrm{T}-\mathrm{I}-\mathrm{V}$ model. The target cell subpopulation (T) is cells in several organs, such as the lungs, heart, arteries, intestines and kidneys. The Infected cell subpopulation (I) is a cell that is infected through a receptor on the surface called Angiotensin Converting Enzyme 2 (ACE2) (Diaz, 2020). Target cells were epithelial cells in all of these organs. This target cell was ACE2. The conversion of angiotensin II (vasoconstruction peptide) to angiotensin
1-7 (vasodilator) was catalyzed by ACE2 (Zhang et. al., 2020). $83 \%$ of normal lung cells express ACE2, namely type II alveolar epithelial cells (AECII), which make these cells viral reservoirs. The spike protein (shaped like a nail) stuck to the surface of the SARS-CoV virus (Zoufaly et. al., 2020). The ACE2 enzyme attaches to the cell membranes of several organs (Bourgonje et. al, 2020).

\section{STABILITY ANALYSIS}

The Mathematical Model obtained in System (1) refers to Du and Yuan's (2020) paper.

$$
\begin{aligned}
& \frac{d T}{d t^{\prime}}=(d \tau) T_{0}-(d \tau) T-\frac{(k \tau)}{A \alpha} V T \\
& \frac{d I}{d t^{\prime}}=\frac{(k \tau)}{A \alpha} V T-(\delta \tau) I \\
& \frac{d V}{d t^{\prime}}=(p \tau) I-(c \tau) V
\end{aligned}
$$

Description of the target cell subpopulation, Covid19 infected cells, virus population and parameters are shown in Table 1. 
Table 1. Target cell subpopulation, Covid-19 infected cells, virus population and parameters.

\begin{tabular}{|c|c|c|c|}
\hline No. & Symbol & Explanation & Unit \\
\hline 1 & $\tau$ & $\begin{array}{l}\text { Average cycle time for viral } \\
\text { replication }\end{array}$ & day \\
\hline 2 & $t^{\prime}=t / \tau$ & $\begin{array}{l}\text { Number of virus replication } \\
\text { cycles }\end{array}$ & - \\
\hline 3 & $T$ & Number of target cells at $t^{\prime}$ & cell \\
\hline 4 & $I$ & Number of infected cells at $t^{\prime}$ & cell \\
\hline 5 & $V$ & Number of virus particles at $t^{\prime}$ & virus \\
\hline 6 & $(d \tau)$ & $\begin{array}{l}\text { Target cells die during each } \\
\text { cycle }\end{array}$ & - \\
\hline 7 & $T_{0}$ & Number of target cells at $t^{\prime}=0$ & cell \\
\hline 8 & $(k \tau)$ & $\begin{array}{l}\text { Target cells infected during } \\
\text { each cycle based on virion unit } \\
\text { density }\end{array}$ & - \\
\hline 9 & $A$ & $\begin{array}{l}\text { Effective surface area of the } \\
\text { network }\end{array}$ & $m m^{2}$ \\
\hline 10 & $\alpha$ & $\begin{array}{l}\text { The ratio of the number of } \\
\text { virus particles to the number of } \\
\text { virions }\end{array}$ & $\begin{array}{l}\text { virus } \\
/ \mathrm{mm}^{2}\end{array}$ \\
\hline 11 & $(\delta \tau)$ & $\begin{array}{l}\text { Infected cells die during each } \\
\text { cycle }\end{array}$ & - \\
\hline 12 & $(p \tau)$ & $\begin{array}{l}\text { The number of virus particles } \\
\text { produced by each infected cell } \\
\text { during each cycle }\end{array}$ & - \\
\hline 13 & $(c \tau)$ & $\begin{array}{l}\text { Virus particles die during each } \\
\text { cycle }\end{array}$ & - \\
\hline
\end{tabular}

Theorem 1. Equilibrium Point

There are two equilibrium points of System (1), namely: free from the Covid-19 virus and infected with the Covid-19 virus. The Covid-19 virus-free equilibrium point is

$$
E P_{0}=(T, I, V)=\left(T_{0}, 0,0\right) .
$$

The equilibrium point for contracting the Covid-19 virus is

$$
E P_{1}=(T, I, V)=\left(a_{1}, a_{2}, a_{3}\right),
$$

where

$a_{1}=\frac{A \alpha(\delta \tau)(c \tau)}{(k \tau)(p \tau)}$,

$a_{2}=\frac{(k \tau)(d \tau) T_{0}(p \tau)-(\delta \tau)(c \tau)(d \tau) A \alpha}{(p \tau)(\delta \tau)(k \tau)}$,

$a_{3}=\frac{(k \tau)(d \tau) T_{0}(p \tau)-(\delta \tau)(c \tau)(d \tau) A \alpha}{(\delta \tau)(c \tau)(k \tau)}$.

\section{Proof.}

From Equation (1a) and $\frac{d T}{d t \prime}=0$, we get

$T=\frac{(d \tau) T_{0} A \alpha}{(d \tau) A \alpha+(k \tau) V}$

From Equation (1c) and $\frac{d V}{d t \prime}=0$ obtained

$I=\frac{(c \tau)}{(p \tau)} V$

From $\frac{d I}{d t \prime}=0$ and substituting equations (2) and (3) into equation (1), we get
$V=0$

or $V=\frac{(d \tau)\left[(k \tau) T_{0}(p \tau)-(\delta \tau)(c \tau) A \alpha\right]}{(\delta \tau)(c \tau)(k \tau)}=a_{3}$

From Equation (2) and Equation (4), we get

$T=T_{0}$.

From Equation (3) and Equation (4), we get

$I=0$.

From Equations (6), (7) and (4) it is proven that the Covid-19 virus-free equilibrium point is $E P_{0}$.

If Equation (5) is substituted into Equation (2), then we get

$T=\frac{A \alpha(\delta \tau)(c \tau)}{(k \tau)(p \tau)}=a_{1}$

If Equation (8) is substituted into Equation (3), then we get

$I=\frac{(k \tau)(d \tau) T_{0}(p \tau)-(\delta \tau)(c \tau)(d \tau) A \alpha}{(p \tau)(\delta \tau)(k \tau)}=a_{2}$

From Equations (8), (9) and (5) it is proven that the equilibrium point for contracting the Covid-19 virus is $E P_{1}$.

From Theorem 1 it can be conveyed, if there is no Covid-19 virus then someone will be safe or someone is virus free, and if there is a virus then a person's healing point is influenced by all parameters. Virus-free can be achieved if there is no person carrying the virus or complying with health procedures such as wearing a mask, keeping a distance and washing hands as often as possible. When a person gets a virus, only the immune (target cells) can fight the infected cells.

Theorem 2. Existence of the Equilibrium Point Existence $E P_{0}$ fulfilled in any non-negative number parameter and existence $E P_{1}$ fulfilled if

$$
(k \tau) T_{0}(p \tau)-(\delta \tau)(c \tau) A \alpha>0 .
$$

\section{Proof.}

From Theorem 1, that existence $E P_{0}$ and $E P_{1}$ proven. From Theorem 2 it can be seen that all parameters do not affect the existence of the equilibrium point $E P_{0}$. All parameters are target cells die during each cycle, number of target cells at $t^{\prime}=0$, target cells infected during each cycle based on virion unit density, effective surface area of the network, the ratio of the number of virus particles to the number of virions, infected cells die during each cycle, the number of virus particles produced by each infected cell during each cycle, and virus particles die during each cycle. This means that if a person is not exposed to the Covid-19 virus, the target cells would not affected or the condition of a person is healthy without the virus. For someone who is infected with the virus, all parameters affect the existence of the equilibrium point $E P_{0}$. This means that a person's condition will remain 
healthy or even die depending on the target cells working well or not.

Theorem 3. Stability of the Equilibrium Point

(1) If $\sqrt{((\delta \tau)-(c \tau))^{2}+4 \frac{(k \tau)(p \tau) T_{0}}{A \alpha}}-((\delta \tau)+(c \tau))$, then the equilibrium point $E P_{0}$ is locally asymptotically stable.

(2) If

$$
\sqrt{((\delta \tau)-(c \tau))^{2}+4 \frac{(k \tau)(p \tau)\left(a_{1}\right)}{A \alpha}}-((\delta \tau)+
$$

$(c \tau))<0$, then the equilibrium point $E P_{1}$ is locally asymptotically stable.

\section{Proof.}

For example, in System (1) it is written

$f_{1}=\frac{d T}{d t^{\prime}}=(d \tau) T_{0}-(d \tau) T-\frac{(k \tau)}{A \alpha} V T$

$f_{2}=\frac{d I}{d t^{\prime}}=\frac{(k \tau)}{A \alpha} V T-(\delta \tau) I$

$f_{3}=\frac{d V}{d t^{\prime}}=(p \tau) I-(c \tau) V$

Jacobian matrix function $f$ from System (10) written can be obtained by first performing the partial derivation of the functions

$$
\begin{aligned}
& f_{1}=(T, I, V) \\
& f_{2}=(T, I, V) \\
& f_{3}=(T, I, V)
\end{aligned}
$$

as follows.

(i). Partial derivative $f_{1}$ with respect to $T, I, V$ namely:

$$
\frac{\partial f_{1}}{\partial T}=-(d \tau)-\frac{(k \tau)}{A \alpha} V ; \quad \frac{\partial f_{1}}{\partial I}=0 ; \quad \frac{\partial f_{1}}{\partial V}=0 ;
$$

(ii). Partial derivative $f_{2}$ with respect to $T, I, V$ namely:

$$
\frac{\partial f_{2}}{\partial T}=\frac{(k \tau)}{A \alpha} V ; \quad \frac{\partial f_{2}}{\partial I}=-(\delta \tau) ; \quad \frac{\partial f_{2}}{\partial V}=\frac{(k \tau)}{A \alpha} T ;
$$

(iii). Partial derivative $f_{3}$ with respect to $T, I, V$ namely:

$$
\frac{\partial f_{3}}{\partial T}=0 ; \quad \frac{\partial f_{3}}{\partial I}=(p \tau) ; \quad \frac{\partial f_{3}}{\partial V}=-(c \tau) ;
$$

The Jacobian matrix is

$$
J(T, I, V)=\left[\begin{array}{ccc}
-(d \tau)-\frac{(k \tau)}{A \alpha} V & 0 & 0 \\
\frac{(k \tau)}{A \alpha} V & -(\delta \tau) & \frac{(k \tau)}{A \alpha} T \\
0 & (p \tau) & -(c \tau)
\end{array}\right]
$$

\section{(1) For $E_{0}$, we get}

$$
J\left(T_{0}, 0,0\right)=\left[\begin{array}{ccc}
-(d \tau) & 0 & 0 \\
0 & -(\delta \tau) & \frac{(k \tau)}{A \alpha}\left(T_{0}\right) \\
0 & (p \tau) & -(c \tau)
\end{array}\right]
$$

We find the eigenvalues of $J\left(T_{0}, 0,0\right)$ that is $\lambda_{i}$, for $i=$ $1,2,3$, where

$$
\left|J\left(T_{0}, 0,0\right)-\lambda I\right|=0 .
$$

We get the eigenvalues of the Jacobian Matrix which is represented by

$\lambda_{1}=-(d \tau)$,

$\lambda_{2}=\frac{1}{2}\left[-((\delta \tau)+(c \tau))-\sqrt{((\delta \tau)-(c \tau))^{2}+4 \frac{(k \tau)(p \tau) T_{0}}{A \alpha}}\right]$,

$\lambda_{3}=\frac{1}{2}\left[-((\delta \tau)+(c \tau))+\sqrt{((\delta \tau)-(c \tau))^{2}+4 \frac{(k \tau)(p \tau) T_{0}}{A \alpha}}\right]$.

We know that $((\delta \tau)-(c \tau))^{2} \geq 0$ and $\frac{(k \tau)(p \tau) T_{0}}{A \alpha}>0$, so that $((\delta \tau)-(c \tau))^{2}+4 \frac{(k \tau)(p \tau) T_{0}}{A \alpha}>0$.

Since the parameters are greater than zero, we get

$$
\lambda_{1}<0, \quad \lambda_{2}<0,
$$

and because

$$
\sqrt{((\delta \tau)-(c \tau))^{2}+4 \frac{(k \tau)(p \tau) T_{0}}{A \alpha}}-
$$

$((\delta \tau)+(c \tau))<0$, then we get $\lambda_{3}=\frac{1}{2}[-((\delta \tau)-$ $(c \tau)) \pm$

$\left.\sqrt{((\delta \tau)-(c \tau))^{2}-4\left((\delta \tau)(c \tau)-\frac{(k \tau)(p \tau) T_{0}}{A \alpha}\right)}\right]<0$.

We get all negative eigenvalues, so that $E P_{0}$ is locally asymptotically stable.

(2) For EP 1 , we get

$$
J\left(a_{1}, a_{2}, a_{3}\right)=\left[\begin{array}{ccc}
-(d \tau)-\frac{(k \tau)}{A \alpha}\left(a_{3}\right) & 0 & 0 \\
\frac{(k \tau)}{A \alpha}\left(a_{3}\right) & -(\delta \tau) & \frac{(k \tau)}{A \alpha}\left(a_{1}\right) \\
0 & (p \tau) & -(c \tau)
\end{array}\right]
$$

We find the eigenvalues of $J\left(a_{1}, a_{2}, a_{3}\right)$ that is $\lambda_{i}$, for $i=1,2,3$, where

$$
\left|J\left(a_{1}, a_{2}, a_{3}\right)-\lambda I\right|=0 .
$$

We get the eigenvalues of the Jacobian Matrix which is represented by

$$
\begin{aligned}
& \lambda_{1}=-\left((d \tau)+\frac{(k \tau)}{A \alpha}\left(a_{3}\right)\right), \\
& \lambda_{2}=\frac{1}{2}\left[-((\delta \tau)+(c \tau))-\sqrt{((\delta \tau)-(c \tau))^{2}+4 \frac{(k \tau)(p \tau)\left(a_{1}\right)}{A \alpha}}\right], \\
& \lambda_{3}=\frac{1}{2}\left[-((\delta \tau)+(c \tau))+\sqrt{((\delta \tau)-(c \tau))^{2}+4 \frac{(k \tau)(p \tau)\left(a_{1}\right)}{A \alpha}}\right]
\end{aligned}
$$

We know that $((\delta \tau)-(c \tau))^{2} \geq 0$ and $\frac{(k \tau)(p \tau) T_{0}}{A \alpha}>0$, so $((\delta \tau)-(c \tau))^{2}+4 \frac{(k \tau)(p \tau) T_{0}}{A \alpha}>0$.

Since the parameters are greater than zero, we get

$$
\lambda_{1}<0, \lambda_{2}<0
$$


and because $\sqrt{((\delta \tau)-(c \tau))^{2}+4 \frac{(k \tau)(p \tau)\left(a_{1}\right)}{A \alpha}}-$ $((\delta \tau)+(c \tau))<0$, then we get

$\lambda_{3}=\frac{1}{2}\left[-((\delta \tau)+(c \tau))+\sqrt{((\delta \tau)-(c \tau))^{2}+4 \frac{(k \tau)(p \tau)\left(a_{1}\right)}{A \alpha}}\right]<0$.

We get all negative eigenvalues, so that $E P_{1}$ is locally asymptotically stable.

From Theorem 3 the stability point is affected by all parameters. This means that a person will recover depending on the target cells that work. The better the target cells work, the healthier the person would be and those who have been infected with Covid-19 will recover.

\section{SIMULATION}

The parameters in this simulation are taken from $\mathrm{Du}$ and Yuan's (2020) paper. Table 2 shows the parameter values. In this simulation, we replace the symbol $(p \tau)$ with $b$. This is because in Matlab there is no Insert Legend that can be written $(p \tau)$.

Table 2. Parameter values for simulation.

\begin{tabular}{|c|c|c|}
\hline No. & Parameter & Value \\
\hline 1 & $\tau$ & 7 \\
\hline 2 & $d \tau$ & $2 \times 10^{-4}$ \\
\hline 3 & $T_{0}$ & $10^{8}$ \\
\hline 4 & $\frac{(k \tau)}{A \alpha} T_{0}$ & 0.075 \\
\hline 5 & $\delta \tau$ & 0.4 \\
\hline 6 & $c \tau$ & 0.4 \\
\hline 7 & $I_{0}$ & 10 \\
\hline 8 & $V_{0}$ & 100 \\
\hline
\end{tabular}

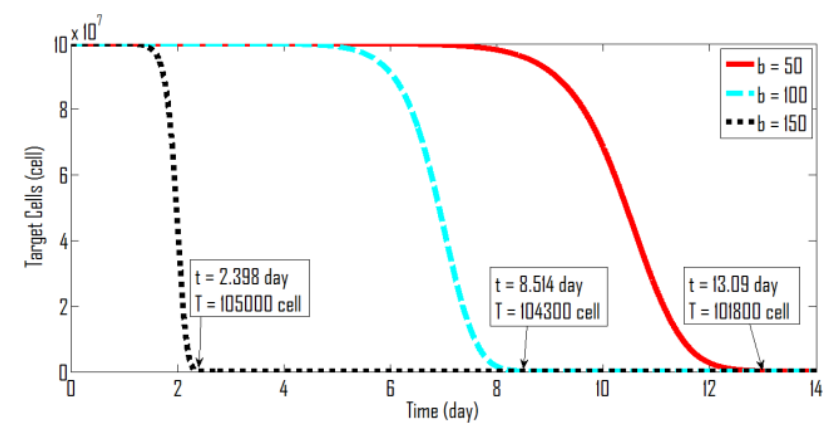

Figure 1. Changes in the number of target cells against the presence of the Covid-19 virus.

Target cells reflect the number of cells in people with three conditions, namely: low, moderate and high immunity conditions. Figure 1, Figure 2 and Figure 3 represent person with high immunity $((p \tau)=b=50)$, moderate immunity $((p \tau)=b=100)$, and low immunity $\quad((p \tau)=b=150)$. Person with good immunity shows the target cell from 10,000,000 cells in 13.09 days to 101,800 cells. Person with moderate immunity shows the target cell from 10,000,000 cells in
8,514 days to 104,300 cells. Person with low immunity shows the target cell from $10,000,000$ cells in 2,398 days to 105,000 cells. The order of decline in target cells from the longest to the fastest is good, medium and low immunity. Table 3 describes the descending order of the target cells.

Table 3. Target cell decrease.

\begin{tabular}{lllll}
\hline No. & Immunity & $\begin{array}{l}\text { Initial } \\
\text { amount } \\
\text { (cell) }\end{array}$ & $\begin{array}{l}\text { Total Ten } \\
\text { Thousand } \\
\text { (cell) }\end{array}$ & $\begin{array}{l}\text { Time } \\
\text { (day) }\end{array}$ \\
\hline 1 & High & $10,000,000$ & 101,800 & 13.09 \\
2 & Medium & $10,000,000$ & 104,300 & 8.514 \\
3 & Low & $10,000,000$ & 105,000 & 2.398 \\
\hline
\end{tabular}

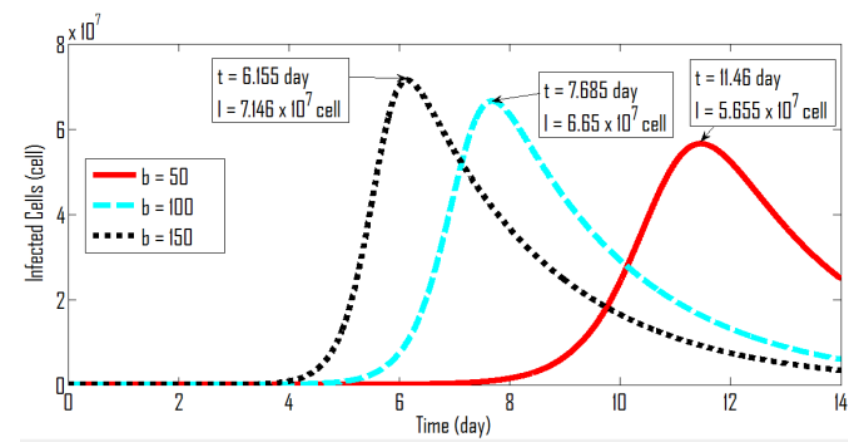

Figure 2. Changes in the number of infected cells against the presence of the Covid-19 virus.

Figure 2 shows the peak number of infected cells differed between individuals with high, moderate and low immunity. A person with low immunity on day 6,155 the number of infected is $7.146 \times 10^{7}$ cell. A person with moderate immunity on day 7,685 the number of infected is $6.65 \times 10^{7}$ cell. A person with high immunity on day 11.46 the number of infected is $5.655 \times 10^{7}$ cell. Briefly, this explanation is in Table 4 .

Table 4. Increase in the number of infected cells.

\begin{tabular}{llll}
\hline No. & Immunity & $\begin{array}{l}\text { Highest number of cells } \\
\text { (cell) }\end{array}$ & $\begin{array}{l}\text { Time } \\
\text { (day) }\end{array}$ \\
\hline 1 & High & $5.655 \times 10^{7}$ & 11.46 \\
2 & Medium & $6.65 \times 10^{7}$ & 7.685 \\
3 & Low & $7.146 \times 10^{7}$ & 6.155 \\
\hline
\end{tabular}

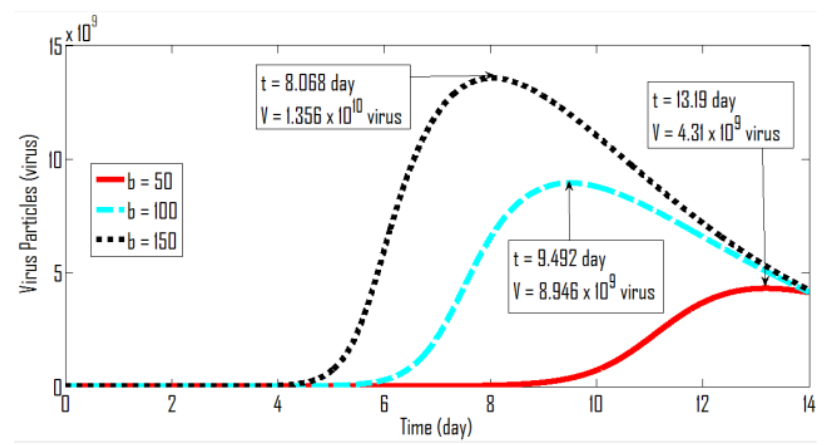

Figure 3. Changes in the number of virus particles. 
Figure 3 shows the number of viruses with high, medium and low immunity conditions. For someone with high immunity the maximum virus count on day 13.19 is $4.31 \times 10^{8}$ virus. For someone with moderate immunity the maximum virus count on 9,492 days is $8.946 \times 10^{9}$ virus. For a person with low immunity the maximum viral load on day 8,068 is $1.356 \times 10^{10}$ virus. Table 5 describes the amount of virus in the condition of a person with high, medium and low immunity.

Table 5. Increase in the number of virus particles.

\begin{tabular}{llll}
\hline No. & Immunity & $\begin{array}{l}\text { Highest number of } \\
\text { viruses (virus) }\end{array}$ & Time (day) \\
\hline 1 & High & $4.31 \times 10^{8}$ & 13.19 \\
2 & Medium & $8.946 \times 10^{9}$ & 9.492 \\
3 & Low & $1.356 \times 10^{10}$ & 8.068 \\
\hline
\end{tabular}

\section{CONCLUSION}

The stability of being free of the Covid-19 virus and infected with the virus is influenced by all parameters. The number of target cells, virus-infected cells and virus particles is affected by a person's immunity. If a person has high immunity, the number of target cells would decrease slowly. Vice versa, if a person has low immunity, then the number of target cells will drop rapidly. In a person having low immunity, the infected cells and viruses will quickly increase in number compared to the one with high immunity.

Conflicts of Interest: MJL is on the editorial board of the Biology, Medicine, \& Natural Product Chemistry, and was recused from this article's review and decision. The authors declare that there are no conflicts of interest.

\section{REFERENCES}

Bourgonje, A. R., Abdulle, A. E., Timens, W., Hillebrands, J. L., Navis, G. J., Gordijn, S. J., ... \& van Goor, H. (2020). Angiotensin-converting enzyme 2 (ACE2), SARS-CoV-2 and the pathophysiology of coronavirus disease 2019 (COVID-19). The Journal of pathology, 251(3), 228-248.

Diaz, J. H. (2020). Hypothesis: angiotensin-converting enzyme inhibitors and angiotensin receptor blockers may increase the risk of severe COVID-19. Journal of travel medicine.

Du, S. Q., \& Yuan, W. (2020). Mathematical modeling of interaction between innate and adaptive immune responses in COVID-19 and implications for viral pathogenesis. Journal of medical virology, 92(9), 1615-1628.

Sugiyanto, S., \& Abrori, M. (2020). A mathematical model of the COVID-19 cases in Indonesia (under and without lockdown enforcement). Biology, Medicine, \& Natural Product Chemistry, 9(1), 15-19.

Tan, W., Zhao, X., Ma, X., Wang, W., Niu, P., Xu, W., ... \& Wu, G. (2020). A novel coronavirus genome identified in a cluster of pneumonia cases-Wuhan, China 2019-2020. China CDC weekly, 2(4), 61-62.

Zhang, X., Li, S., \& Niu, S. (2020). ACE2 and COVID-19 and the resulting ARDS. Postgraduate medical journal, 96(1137), 403-407.

Zoufaly, A., Poglitsch, M., Aberle, J. H., Hoepler, W., Seitz, T., Traugott, M., ... \& Penninger, J. M. (2020). Human recombinant soluble ACE2 in severe COVID-19. The Lancet Respiratory Medicine, 8(11), 1154-1158. 
THIS PAGE INTENTIONALLY LEFT BLANK 